\title{
As raízes de Paulo Honório: uma leitura de São Bernardo a partir de Raízes do Brasil
}

\begin{abstract}
Alexandre Lobo*
Resumo: Este trabalho analisa a obra de Graciliano Ramos, São Bernardo, a partir do conceito de Homem Cordial presente na obra de Sérgio Buarque de Holanda, em Raízes do Brasil. Inseridas no contexto pós Revolução de 30, ambas as obras contribuem para o debate sobre a identidade nacional na medida em que retratam a passagem de um Brasil arcaico, rural a um Brasil capitalista, embora com um tipo de

Abstract: This work analyzes Graciliano Ramos's book, São Bernardo, from the concept of Cordial Man present in Sergio Buarque de Holanda's work, Raízes do Brasil. Inserted in the post thirty's Revolution context, both books contribute to the debate on the national identity as they portray the transition of a Brazil archaic, rural to a capitalist one, even with its own type of capitalism, heir of a slavocrat society.
\end{abstract} capitalismo próprio, herdeiro de uma sociedade escravocrata.

Palavras-chave: cordialidade; identidade; nacional; modernidade.

Antonio Candido nos diz que, no Brasil, ao contrário do que ocorre na Europa, onde a análise social é desenvolvida pela sociologia e filosofia, aqui, inicialmente, é a literatura o local de reflexão social e somente depois é que a teoria aborda o que já foi trabalhado pela literatura. A chamada “geração de 30" é um exemplo disto, principalmente Graciliano Ramos com suas obras São Bernardo e Vidas Secas. Se a segunda é marcada por uma forte crítica social ao retratar a vida de retirantes nordestinos, enfrentando o abandono das autoridades políticas e a exclusão social; a primeira retrata as relações cordiais ${ }^{1}$ de um fazendeiro que teve uma ascensão social por meios nada exemplares. Na obra de Graciliano Ramos, podemos achar elementos, característicos da realidade social brasileira, que comporão, poucos anos depois, a análise precursora de Sérgio Buarque de Holanda em Raízes do Brasil. Esta obra, por sua vez, ao lado de Casa-Grande e Senzala, de Gilberto Freyre, e Formação do Brasil Contemporâneo, de Caio Prado Jr. são fundamentais para a compreensão da formação do Brasil.

\footnotetext{
* Mestre e Licenciado em História, UFRGS, Bacharel e Licenciado em Ciências Sociais, UFRGS e professor de História da Rede Pública do Estado do Rio Grande do Sul. E-mail: webhumanas@yahoo.com.br.

$1 \mathrm{O}$ termo cordial aqui tem o sentido dado por Sérgio Buarque de Holanda. Tal conceito será abordado mais adiante.
} 
São Bernardo e Raízes do Brasil são obras inseridas no debate a respeito da identidade nacional. Tanto a obra de Graciliano Ramos, publicada em 1934, quanto a de Sérgio Buarque de Holanda, publicada em 1936, refletem o Brasil dos coronéis, dos caudilhos e, ao mesmo tempo, as promessas da chamada Revolução de 30 e o legado da Semana da Arte Moderna: a expectativa de uma ruptura com o Brasil Arcaico. Por serem contemporâneas, estas obras apresentam preocupações semelhantes. Em perspectivas diferentes, uma de cunho mais teórico, embora ensaístico, e a outra literária, permitem a reflexão a respeito das relações sociais e políticas no Brasil, tanto dos anos 30 quanto do atual. Se de um lado, Sérgio Buarque de Holanda nos fornece um arsenal conceitual, a análise da obra de Graciliano Ramos nos fornece um exemplo, por meio da trajetória, das relações e do meio social de seu personagem Paulo Honório, de como aqueles conceitos podem ser usados na compreensão da sociedade brasileira. Não que fosse esta a intenção do literato, demonstrar conceitos, mas, provido de uma sensibilidade aguçada, sua obra é a expressão da reflexão a respeito da realidade social em que vivia, e, neste sentido, é composta de um material semelhante ao do de Sérgio Buarque de Holanda.

Modernista, mas não mais entendendo o estético como principal instrumento revolucionário, tal como entendia a "Semana da Arte Moderna de 22", Graciliano Ramos, assim como outros escritores da geração de trinta, tem uma literatura preocupada com as questões sociais. Desta forma fazia de seus escritos uma denúncia, tanto das desigualdades sociais quanto do nosso processo de modernização tupiniquim. Não bastava mais ser moderno, "industrioso" e urbano, tinha de haver uma maior eqüidade social. A modernidade pela modernidade, como se revelaria tempos depois da obra de Graciliano, traria não o paraíso, não a solução para os problemas do Brasil, mas o êxodo rural e o desemprego nas grandes cidades, modernidade essa que só se efetivaria na vida de poucos brasileiros.

A chamada "Revolução de 30" não foi uma revolução no sentido clássico, aquele atribuído à Revolução Francesa, Russa ou Inglesa, não significou uma ruptura radical com determinada estrutura social e de uma classe no poder sendo substituída por outra. Entretanto, não foi à toa que ela contou com o apoio de setores ditos progressistas para a época. Tenentistas e modernistas apoiaram o movimento que impediu a posse de Júlio Prestes, candidato paulista ao poder, representante dos velhos setores agrícolas. O novo grupo no poder, encabeçado por Getúlio Vargas, não era uma nova classe, não representava uma nova ruptura, mesmo com apoio de "progressistas" ainda representava as antigas classes rurais, era uma substituição de oligarquias. A compra das safras de café para amortizar os efeitos da crise da bolsa de valores de Nova Iorque é um exemplo disto. Por outro lado, ao longo dos 
quinze anos do primeiro governo Vargas, transformações significativas ocorreram. O governo passou a assumir uma postura mais industrializante, o que não era necessariamente uma novidade, visto que o positivista governo militar Deodoro da Fonseca/Floriano Peixoto, embora sem sucesso, já tinha tal preocupação, mas era agora a construção das bases da indústria que deslancharia nos anos 50/60. Também é inegável a importância do fim do voto descoberto, um dos mecanismos de manutenção de poder dos coronéis, e a inclusão do voto feminino na nova Constituição. Porém, tal revolução desembocaria em uma ditadura e muitos setores, que a apoiaram inicialmente, com ela romperam ao longo do governo Vargas.

Mesmo depois da ascensão de Vargas ao poder, as práticas sociais herdadas das antigas oligarquias continuaram, não mais em termos políticos, mas sim em termos culturais e sociais. O apadrinhamento, por exemplo, ao contrário de extinguir-se, ganhou força com o crescimento do Estado. Na medida em que crescia a quantidade de cargos públicos proporcionalmente ao crescimento do número das estatais, que promoveriam o crescimento industrial brasileiro, o emprego público tornava-se capital, era distribuído na troca de apoio político.

O homem cordial não fora abolido com tal revolução, continuava - e ainda continua presente na vida social e política brasileira. Embora haja um capítulo em Raízes do Brasil intitulado "O homem cordial", não há uma definição de dicionário nem uma conceitualização didática. É do contexto da obra que podemos extrair uma definição. Em linhas gerais, o homem cordial é fruto da colonização portuguesa. A colonização litorânea se deu pela "lei" do pouco esforço. Pouco partidário da ética protestante calvinista e seu trabalho árduo, impulsionado pelo Metalismo do enriquecimento pelo extrativismo, o colonizador era pouco intencionado em produzir, interessado apenas em explorar e extrair, o português, no primeiro século de colonização, não ousou entrar no interior, mas buscou adaptar-se ao meio. Também é pela lei do pouco esforço que o homem cordial prefere sacrificar sua capacidade de exercer a cidadania em troca de alguns favores. $\mathrm{O}$ favor, na cordialidade, tem papel de aliviador de tensões. É um benefício concedido pela parte detentora de poder a um subordinado. O cordial não é apenas o bondoso, o benfeitor ou o amigo fiel, não é apenas aquele concede, mas também aquele que recebe o favor. Ser privilegiado é uma forma de distinção e aparente esperteza. Em uma escala hierárquica, todos ganham uma vantagem, todos burlam, de forma ou de outra, as regras, assim, há um comprometimento generalizado com o sistema de favor. A cordialidade não é apenas uma forma de relação entre subordinados e superiores, mas uma cultura, uma prática que se mantém pervertendo a idéia de democracia e igualdade. E é justamente por isso que pode passar desapercebida, como se fosse natural. 
Avesso ao trabalho árduo, com visão de curto prazo, mas sem percepção das conseqüências a longo prazo, assim é o homem cordial. Defensor da democracia e da liberdade, seu discurso não condiz com sua prática. Para os dominantes, trata-se de uma forma de permanência e legitimação do poder por meio da amizade, da cordialidade e da distribuição de favores. Diferentes favores são distribuídos a subordinados diferentes. Do outro lado, trata-se de amenizar a dominação, da recepção de migalhas do que seria direito ou mesmo de privilégios em relação a outros do mesmo nível que tornam a ausência de reais direitos mais suportável.

Para Sérgio Buarque de Holanda, a cordialidade faz parte do caráter do brasileiro. Não como uma essência, pois, se assim fosse, seria impossível querer transformá-la, mas como parte de uma prática cultural com origens no início de nossa colonização. Não se trata da cordialidade entendida como bondade, mas de uma estrutura social baseada nas relações sociais em que o pessoal e o personalismo imperam sobre o público e o coletivo. Individualista e personalista, o homem cordial torna o que seria público numa extensão de seu patrimônio. Ocupa-se um posto público de comando, seu trabalho transforma-se de obrigação a concessão. Os recursos públicos confundem-se com os privados como se determinada realização ocorresse a partir da partilha de bens particulares do governante. Não é o governo ou o Estado que realiza uma obra pública, mas o indivíduo que se esquece do lugar que ocupa. O usuário do serviço público transforma-se de cidadão em aquele que tem direito à cidade. É o homem cordial aquele que distribui cargos públicos ou benefícios como benfeitor, mas, em troca, espera criar uma dependência útil dos beneficiados. Quando detentor de cargos públicos, o homem cordial realiza políticas públicas em seu próprio nome, como se fizesse um favor. "A escolha dos nomes que irão exercer funções públicas faz-se de acordo com a confiança pessoal que merecem os candidatos, e muito menos de acordo com suas capacidades próprias" (HOLANDA, 1998. p.146). A cordialidade, fortemente emocional, impede o desenvolvimento da democracia na medida em que transforma o que seria de direito em concessão e torna os iguais mais próximos pessoalmente dos detentores em "mais iguais". A hierarquia social mascara-se no personalismo dos dirigentes e dominantes.

Mudam-se os governantes, mas a sociedade continua a mesma, persiste o homem cordial. A "Revolução de 30" trocou nomes no poder, passou de um federalismo a um centralismo, mas manteve as mesmas classes no poder com suas velhas práticas. O que ocorre é uma alternância de poder entre as facções das mesmas classes.

É nesse Brasil de rupturas, mas sem radicais transformações estruturais, que se insere o personagem de Graciliano. Embora sua narrativa ocorra logo após a "Revolução de 30", sua 
trajetória percorre o período da República Velha. Nesse contexto de transformações sociais e políticas, cabe perguntar quem é Paulo Honório e o que representa em termos sociais. Homem prático, de pouca literatura, este personagem singular de Graciliano Ramos tem uma origem humilde, mas tem uma ascensão social em um Brasil aparentemente não estratificado, que permite o enriquecimento com trabalho. É importante lembrar que, mesmo sem estudo formal, alfabetizado na cadeia, era leitor de revistas técnicas e é capaz de crítica ante um livro encomendado aos moldes da divisão social de trabalho fordista. Ao considerar tal livro encomendado "acanalhado", de uma linguagem inadequada, ele mesmo o escreveu.

Embora trabalhador, não foi pelo trabalho que Paulo Honório enriqueceu. Desmentindo o discurso do enriquecimento pelo trabalho, reflete: "Tenho visto criaturas que trabalham demais e não progridem. Conheço indivíduos preguiçosos que têm faro: quando a ocasião chega, desenrolam-se, abrem a boca - engolem tudo" (RAMOS, 2002. p.39). Para enriquecer, não basta ser trabalhador como seu fiel capataz, Casimiro Lopes, mas é preciso um pouco de sorte, manter as relações certas e, no seu caso, fugir um pouco dos preceitos éticos. O que é ter faro sem ter vocação para o trabalho? Que tipo de circunstância proporciona "engolir tudo"? Paulo Honório não nos revela, não era seu caso, mas em seu contexto podemos deduzir que é aquele que nasceu em condições econômicas favoráveis, aquele que esperou ser favorecido por um conjunto de relações que lhe pudesse dar um cargo público rendoso ou aquele que não perde uma oportunidade de cometer alguma irregularidade que possa lhe favorecer. Seu ideal é "colher o fruto sem plantar a árvore" (HOLANDA, 1989, p.44). Trata-se do tipo especulador, aventureiro que espera a riqueza sem trabalho, sem esforço.

Rural, Paulo Honório é agarrado à terra, mas nem por isso é desprovido de um espírito capitalista, empreendedor. Até seu casamento assume o caráter burguês de proliferação da família e perpetuação da propriedade: "Amanheci um dia pensando em me casar [...]. Não me ocupo com amores [...] o que sentia era desejo de preparar herdeiro para São Bernardo" (RAMOS, 2002, p.57). Segundo Antonio Candido, “o próximo lhe interessa na medida em que está ligado aos seus negócios, e, na ética dos números, não há lugar para o desinteresse" (CANDIDO, 1992, p.24). Como capitalista, representa o próprio capitalismo brasileiro, o que alguns chamariam de pré-capitalismo. Ou seja, ele é guiado pelo lucro, mas especificamente o rural; não é como o capitalista plenamente desenvolvido, no modelo inglês pós-Revolução Industrial, para quem não importa a origem do lucro, seja agrícola, industrial ou financeiro. No capitalismo plenamente desenvolvido, em que tudo vira mercadoria, não há ligação emocional entre o capitalista e seu capital. Paulo Honório, ao contrário, não por acaso, 
empenhou-se em conquistar São Bernardo, local em que trabalhava na juventude: "Resolvi estabelecer-me aqui na minha terra [...] e logo planeei adquirir São Bernardo" (RAMOS, 2002. p.14). "Meu fito vida foi conquistar São Bernardo" (RAMOS, 2002 p.3). Este fato levou-o a desejar e dedicar-se ao seu objeto de lucro. A fazenda, para ele, é algo único e insubstituível, mas valiosa que as pessoas e mesmo que Madalena, professora primária com quem casou: "Professorinhas de primeiras letras a escola normal fabrica às dúzias. Uma propriedade como S. Bernardo era diferente" (RAMOS, 2002. p.116). A emotividade sobreposta à racionalidade. O uso de São Bernardo é racional, acumula bens e riquezas para Paulo Honório. Das terras, antes abandonadas por um antigo oligarca, há produção de algodão para fábricas de tecidos. Mas a fazenda é também um limite. O personagem de Graciliano não consegue nem mesmo tenta romper com sua origem, a ela está preso e sacrificando a própria possibilidade de felicidade, sua e alheia, levando inclusive Madalena ao suicídio. Talvez São Bernardo represente a Paulo Honório justamente um misto de sentimento de vingança e de superação de sua condição de classe, por isso sua obstinação com aquelas terras. A fazenda era "um prolongamento dele próprio, era a vitória concreta da sua vitória sobre os homens e obstáculos de vários portes..." (CANDIDO, 1992. p.30). Adquirir, ter e fazer prosperar era uma forma de superar, concreta e simbolicamente, carências impostas pela origem social de Paulo Honório.

As antigas oligarquias, representadas por personagens como Padilha e Mendonça, herdeiras da colonização, são adeptas do pouco esforço e lucro máximo. Acostumadas com a prática extrativa ou com a exploração exaustiva de terceiros como seus prováveis antepassados exploravam seus escravos. Sem raízes nas antigas oligarquias, Paulo Honório não é um exemplo de semeador como descreve Buarque, não quer o lucro fácil, tem de trabalhar a terra além de apenas colher. É adepto ao trabalho, à labuta que a terra exige, além da visão da necessidade de diversificar sua produção. Talvez porque sua origem seja a mesma dos que estão do outro lado, os trabalhadores, aqueles que trabalham e constroem riquezas e não nas elites tradicionais, acostumadas a atividades extrativas e acomodativas às condições naturais, que o fazem não ser um semelhante ao Padilha ou o Mendonça.

Novo rico, Paulo Honório tem necessidade de afirmar-se socialmente e, para isso, casa com uma moça instruída, Madalena, professora de uma escola pública, que abandona o emprego e seu montepio para trabalhar na escola da fazenda São Bernardo. Com o saber letrado, tem uma relação de conflito: se por um lado, aproximou-se dele; por outro, o considera inútil, deslocado de sua realidade. O saber era mais uma questão de status naquele Brasil arcaico. Novos e antigos ricos gostavam de frases pomposas que teciam uma cultura de 
citações e pouca reflexão. $\mathrm{O}$ bacharelismo era uma maneira de formar uma identidade diversa daquela ligada ao rústico homem do campo. Em uma estrutura social marcada por uma rígida divisão social de traços estamentais entre os que trabalham manualmente e os proprietários, todo o trabalho manual era entendido como degradante inferior. $O$ trabalho mental não necessariamente significava o "amor ao pensamento especulativo [...] mas amor à frase sonora, ao verbo espontâneo e abundante, à erudição ostentosa, à expressão rara" (HOLANDA, 1998. p.83). Por outro lado, havia o sistema de morgadia. Era o primogênito, conhecido como filho do pai, o herdeiro do engenho, aos outros eram destinadas as forças militares ou o clero. Muitos iam à Europa estudar, pois até a vinda de D. João VI, no início do século XIX, não havia universidades, o que gerou, para Sérgio Buarque de Holanda, uma civilização pouco afinada com a reflexão. O trabalho intelectual, aqui, era mais uma forma de distinção do trabalho manual, associado ao trabalho escravo.

A questão do saber, para Paulo Honório, é também uma questão política. Por um lado, casa com uma professora, mas por outro considera o saber formal inútil, sem praticidade, e está munido de exemplos. Em sua visão, seu advogado tornou-se melhor em sua profissão quando esqueceu o que aprendera na faculdade. À exceção de algumas leituras sobre zootecnia, acredita que o conhecimento é essencialmente uma questão prática. Construindo uma escola, seu interesse está além das necessidades sociais, pois considera a instrução uma inutilidade para pessoas simples. Seu interesse é mesmo manter sua relação política com o governador para uma possível troca de favores. Das mulheres que passaram em sua vida, é com a mais instruída que casa, mas a instrução dessa é entendida como uma ameaça, pois, ao invés de facilitar-lhe a vida, complicou-a. Após a morte de Madalena, Paulo Honório reflete que seria melhor ter casado com uma mulher mais simples, que não criaria conflitos nem se preocuparia com o salário de seus funcionários, ou seja, não sofreria com a desigualdade social.

Fugindo do panfletário e do maniqueísmo, Graciliano Ramos nos fornece um personagem complexo, apesar de sua aparente simplicidade de homem prático. Pelos seus feitos, poderíamos julgar Paulo Honório como um homem mau, responsável pelo suicídio de Madalena e com um assassinato nas costas - crime que o levou para cadeia. Foi por meio da exploração da fraqueza de Luiz Padilha, péssimo jogador e filho de Salistino Padilha, o antigo proprietário de São Bernardo, que Paulo Honório se apossou de São Bernardo. Por outro lado, este mesmo personagem, que era capaz de maltratar Marciano, o marido de sua amante, usando para com este violência e chamando-o de molambo, por outro se preocupou em levar para a fazenda a sua madrinha, Margarida, e de permitir uma espécie de pensão a tia de 
Madalena após a morte dessa. Além disso, preocupava-se em proteger as irmãs Mendonça, após a morte do pai destas, da rapinagem que ele mesmo havia realizado.

A racionalidade capitalista em que o lucro está acima de tudo não é total em Paulo Honório, mostra disso é que sua relação com Padilha não caracterizaria uma relação capitalista clássica. Foi por meio de um empréstimo que Padilha perdeu sua fazenda. Honório usa de artimanha ao perceber que o outro não conseguiria saldar suas dívidas e assim acabaria liquidando sua propriedade. Entretanto, se fosse em uma relação capitalista aos moldes inglês, não haveria nenhuma pessoalidade na transação da posse e ambas as partes não manteriam contato. Não é o que ocorre, Padilha é convidado a trabalhar em São Bernardo como professor. Apesar da problemática relação entre ambos, com a suspeita de Padilha ser um revolucionário propagador de ideais socialista, ou mesmo de ser amante de Madalena, ele continua a trabalhar em São Bernardo. De dono de São Bernardo, representante da aristocracia rural brasileira, este personagem transforma-se em um cliente de um exfuncionário.

Como o próprio Paulo Honório afirma, foi além de sua classe, ousou não ser apenas um camponês ou um guia de cego. Com seu complexo de inferioridade - marcado pela questão estética - ascendeu socialmente. Mas a que custo? Era um bruto, sua consciência assim o declarava. Rústico, com poucas mulheres em sua vida, não poderia ter sucesso em sua relação com a professora, e, com o episódio trágico, entrega-se aos efeitos da crise da bolsa de valores, não reagindo à própria derrocada. Poderia reagir, ainda lhe restam recursos, mostra disso é o próprio empreendimento no livro, mas não vê mais sentido nesta acumulação de riqueza, não foi feliz nem promoveu a felicidade alheia.

Abandonado pelos pais, nasceu pobre, entre os de baixo, e desta forma teria fugido da regra, cometido uma infração ao ascender socialmente. Pagou um preço alto, a alienação, ao dedicar-se a São Bernardo, renunciou à felicidade. Seu próprio relacionamento foi realizado sem sentimento. Pensando escolher uma companheira por critérios práticos, Madalena também representava uma superação de seu complexo de inferioridade. A professora, mulher bonita e instruída, estaria acima do que Paulo Honório poderia conquistar se não fosse por sua propriedade. Por diversas vezes Paulo Honório reflete sobre sua feiúra. O dinheiro, sendo conveniente, poderia compensar tudo, comprando, de certa forma, uma mulher bonita e instruída. Mas Madalena não era uma mercadoria. Ela também tinha consciência da falta de amor em relação ao seu marido.

O protagonista de São Bernardo tem uma relação ambígua com Madalena. Incapaz de um gesto carinhoso, preso a sua formação rústica, Paulo Honório a trata sem afeto. Mas se sua 
escolha, aparentemente, foi feita por critérios racionais, no desenrolar da história se manifesta a irracionalidade de um ciúme doentio. O que poderia representar a possível traição de Madalena? A confirmação de sua inferioridade? A perda de uma propriedade? Um dos motivos do casamento de Paulo Honório foi a necessidade de um herdeiro, embora não tenha com este nenhuma identificação. Caso Madalena tivesse um amante, as fraquezas de Honório ficariam mais explícitas, a sua incapacidade para a felicidade, a sua alienação na medida em que sua afetividade foi trocada por uma racionalidade que, a princípio, pensava Paulo Honório, seria vantajoso a ambos. É necessário lembrar que Madalena também tinha origem humilde e foi à custa de trabalho árduo de sua tia que conseguiu concluir seus estudos.

Paulo Honório não é exatamente o homem cordial de Sérgio Buarque de Holanda, pois, como já vimos, sua origem não é nas antigas aristocracias rurais. Por outro lado, o homem cordial, conceito de influência weberiana, é um tipo ideal ${ }^{2}$. Neste sentido, não é necessário que o personagem de Graciliano tenha todas as características do homem cordial para validar o uso de tal conceito na análise de São Bernardo, além disso, é nos personagens em volta de Paulo Honório que podemos encontrar muitos elementos presentes em Raízes do Brasil. Tem relação com políticos, apóia um partido numa troca de interesses, financia um jornal $^{3}$ e constrói uma igreja, tudo isso caracterizando um emaranhado de relações de clientela. Entretanto, ele não tem uma ideologia política clara, uma fidelidade com um jornal, pois inicialmente "ajuda" jornais concorrentes e tem uma religiosidade esporádica, mostrada apenas no momento de seu surto quando Madalena é apenas um corpo estirado na cama. A sua religiosidade, fruto principalmente de seu desespero, ganha expressão na frase que pronuncia repetidas vezes: “A Deus nada é impossível” (RAMOS, 2002, p.168), mas nem por isso tornou-se um freqüentador da Igreja. É também importante manter ligações com o juiz local para, caso uma eventualidade de uma disputa territorial, ter uma sentença favorável. Mendonça, parte das relações de Paulo Honório, como somos levado a entender pela narrativa de Graciliano (RAMOS, 2002, p.182), era quem o aliviava quando levava a cerca de sua propriedade para além do terreno original. O jogo das relações pautadas na troca de favores aliviava a pressão dos credores do dono de São Bernardo: “[...] eu andava assustado com os credores [...] o ativo era maior que o passivo, mas se aqueles malvados quisessem, capavam-

2 Quanto à influência weberiana em Sérgio Buarque de Holanda ver, entre outros autores, REIS, 2000. Para Max Weber, a sociologia, como Ciência Humana, era compreensiva e não explicativa. Neste sentido o conceito de tipo ideal é uma referência a um instrumento de análise, não um conceito essencialista. Ver WEBER, 1982.

3 Vale lembrar que, segundo Renato Ortiz (1995), até a década de 1960 os jornais eram assumidamente partidários. 
me. A escola seria um capital. Os alicerces da igreja eram também capital" (RAMOS, 2002, p.43). Manter relações cordiais com o partido ou com o Governador poderia render influência no meio credor, em troca de votos. A Igreja, assim como a imprensa, também poderia render a formação de uma boa imagem, necessária para a entrada ou permanência no circulo social capaz de trazer privilégios.

Questões poderiam ser levantadas a respeito dos personagens de São Bernardo, como o que levou Madalena a casar. Seu Ribeiro, o guarda-livros de Paulo Honório, conhecedor das leis mas sem o saber formal para o exercício do Direito, por sua vez, reflete uma sociedade em transformação, de um mundo arcaico e rural a um mundo mais moderno e urbano, com outras demandas. Entretanto, tal empenho fugiria dos propósitos do presente trabalho, que é mostrar a aproximação de duas obras clássicas, uma literária, outra teórica. É por meio da análise do ambiente e das relações sociais em São Bernardo que podemos perceber a presença das raízes do Brasil. Ambas as obras, cada uma em seu gênero, são leituras do Brasil. E estas leituras têm em comum uma denúncia de um país que se pretendeu modernista, mas que não se libertou do legado colonial de uma sociedade escravocrata, composta por duas classes sociais díspares e com uma estrutura estatal e política pautada nas relações de influência. Paulo Honório era um desses excluídos que ousou uma ascensão social, mas com o preço da alienação, não apenas sua, mas também de Madalena. E, ao conquistar São Bernardo, tem de infiltrar-se na teia das relações clientelistas, aproximando-se de partidos políticos, mais por conveniência do que convicção ideológica, comprando jornalistas, fazendo-se amigo de juízes e aliando-se ao saber letrado.

\section{Referências}

ARTEAGA, Cristiane Guimarães. A alma russa de um nordestino: Graciliano Ramos leitor de Dostoiévski. 2005. 91f. Dissertação (Mestrado) - Universidade Federal do Rio Grande do Sul, Porto Alegre, 2005.

CANDIDO, Antonio. Literatura e sociedade. São Paulo: Cia. Editora Nacional, 1976. . Ficção e Confissão. Rio de Janeiro: Editora 34, 1992.

COUTINHO, Carlos Nelson. Graciliano Ramos. In: Cultura e sociedade no Brasil. Rio de Janeiro: DP\&A, 2000.

FAUSTO, Boris. História Concisa do Brasil. São Paulo: Edusp, 2001. 
HOLANDA, Sérgio Buarque de. Raízes do Brasil. São Paulo: Cia. das Letras, 1998.

MARANHÃO, Ricardo. História do Brasil, Texto e Consulta. São Paulo: Brasiliense, 1983.

RAMOS, Graciliano. São Bernardo. Rio de Janeiro: Record. 2002.

REIS, José Carlos. Anos 30: Sérgio Buarque de Holanda. In: As identidades do Brasil: de Varnhagen a FHC. Rio de Janeiro: Fundação Getúlio Vargas, 2000.

ORTIZ, Renato. A moderna tradição Brasileira. São Paulo: Brasiliense, 1995.

VELOSO, Mariza e MADEIRA, Angélica. Leituras Brasileiras: Itinerários do pensamento social e na literatura. São Paulo: Paz e Terra, 1999.

WEBER, Max. Ensaios de Sociologia. Rio de Janeiro: Guanabara, 1982. 